\title{
Exploration on Chinese Reading Teaching under the Network Environment
}

\author{
Haibin Yu \\ College of Literature, Bohai University, Jinzhou, 121013, China \\ yu_hb@163.com
}

Keywords: network environment; Chinese reading teaching; explore; implementation strategies

\begin{abstract}
Network reading is a new way of reading which is caused by the change of the text. It refers to the reading activity carried out in the context of network culture. The reading teaching under the network environment reflects more scientific, planning and purpose than the network reading. Integrated network technology into the Chinese reading teaching make the essence of traditional Chinese reading teaching, modern language teaching new ideas and network technology integration, in order to a more efficient and innovative reading teaching mode. In order to improve the teaching effect of Chinese reading under the network environment to research, the research contents include the principle of Chinese reading teaching under the network environment, the cooperative learning mode with group as the main part and the implementation strategies of Chinese reading teaching under the network environment.
\end{abstract}

\section{Introduction}

Reading teaching is the process of dialogue among students, teachers and texts. It is an important way of collecting and processing information, understanding the world, developing thinking and obtaining aesthetic experience. Through reading teaching, so that students learn to read, learn to understand. Through the dialogue between students, teachers and the text, improve students 'feelings, understanding and appreciation ability; cultivate students' lifelong learning ability. Reading teaching is an important part of Chinese teaching. Under the guidance of knowledge-oriented education and examination pressure, traditional Chinese reading teaching mainly focuses on imparting knowledge and coping with examinations, pursuing ready-made and definite knowledge, aiming at ultimate meaning interpretation, overly focusing on a kind of "skill" Training, from reading the content and methods of teaching to evaluation, the formation of an independent system. Teaching process from the article structure and accumulation of knowledge to start, consider the contents of the text points and fragmentary knowledge points. The teaching thought of the teacher follows the train of thought of the article, the student's "study train of thought" follows the teacher's "instructional thinking", and the teaching thought of the teacher is the same as that of the teacher, "Learning" has become a vassal of "teaching". It is not conducive to the active play of students and does not accord with the requirements of constructivist learning.

Network environment refers to the physical distribution of multiple multimedia computers in different locations of the Internet, according to a protocol to communicate with each other, to achieve the hardware and software and network culture sharing system. Network environment not only refers to the network resources and the role of network tools in place, but also includes the learning atmosphere, the learner's motives, interpersonal relationships and teaching strategies and other non-physical form. From the point of view of instructional design, network environment refers more to the combination of network resources and network tools. Network reading is a kind of new reading method brought by the change of culture. It refers to the reading activity in the context of network culture, which is, to acquire the knowledge of multimedia adult synthetic information, including text, by means of computer and network technology, a hypertext reading behavior constructed by meaning. Under the network environment, reading teaching refers to the teaching objectives of the teachers in the network environment, according to the Chinese language curriculum standards, reading content and reading process to students 'self-reading as the main way 
to cultivate students' digital survival ability of teaching activities. Teachers in the teaching process to give full play to the guiding role; the autonomy of students has been fully reflected, to achieve "teaching" as the center to "learning" as the center of the change.

The Chinese course teaching should broaden the field of study and application of Chinese knowledge, pay attention to the interdisciplinary study and the application of modern scientific and technological means, so that students can broaden their horizons and improve their learning efficiency in different content infiltration and integration. The integration of network technology in the teaching of Chinese reading, to seek the intersection of information technology and language teaching, through a new means to break through the traditional teaching of reading the key and difficult to make the essence of traditional Chinese reading teaching, modern Chinese teaching New ideas and network technology, in order to a more efficient and more innovative reading teaching mode, which will become the new century Chinese teaching reform trend of development.

\section{Principles on Chinese Reading Teaching under the Network Environment}

Make great efforts to promote the application of information technology in the teaching process, promote the integration of information technology and subject curriculum, gradually realize the presentation of teaching content, students' learning methods, teachers' teaching methods and teachers 'and students' interactive ways, give full play to information technology The advantages for the students to learn and develop a variety of educational environment and a powerful tool for learning. Under the network environment Chinese reading teaching should follow the following principle:

(1) The combination of knowledge learning and capacity development. With the development of the times and the network into the classroom teaching, the learning center of gravity is no longer just to learn knowledge, but to learn to learn, master the methods and ability to cultivate. Under the network environment, the teaching of reading, pay more attention to master certain knowledge, based on the initiative to find and obtain the necessary knowledge and information. The use of the network to read the teaching process, is full of imagination and continuous innovation process, help students develop innovative spirit and hands-on practical ability.

(2) The unity of instrumentality and humanity. Chinese teaching not only has the function of imparting scientific knowledge and methods, but also bears the important task of humanistic ideological education. In the network teaching, teachers and students face to face communication, teachers often attach importance to the guidance of learning methods, while ignoring the emotional expression between teachers and students. Therefore, we should attach importance to cooperation and emotional exchanges with students. Open reading teaching regards reading process as the process of constructing knowledge, spirit and personality. It is the dialogue between text and reader. On the one hand, the students change the text. On the other hand, the text also changes the students' spiritual world and personality composition.

(3) Promoting the growth of student's wisdom. "Developing students' horizons and developing students' intelligence" is the goal that Chinese teaching syllabuses define for Chinese teaching. Therefore, promoting students' wisdom growth is also an important principle of Chinese reading teaching in network environment. Under the network environment, the teaching of reading is to let students in the process of reading, can not be constrained by the text and some authoritative point of view, in a relaxed and open reading environment, according to their own "pre-experience" and knowledge structure, Text "blank" to question, to fill or even beyond, so that the wisdom of students to "grow."

(4) Combined teachers teaching with network reading. Network reading can not replace the role of teachers, the network environment of Chinese reading teaching, teachers are still teaching the navigator, helpers and participants, give full play to the dynamic role of teachers in the network teaching is the integration of information technology and the core of teaching thought. We should not focus on the actual situation of students, can not use the network resources instead of teachers to explain the inspiration, can not use computer "human-computer interaction" instead of emotional 
exchanges between teachers and students can not only emphasize the teaching capacity and ignore the students thinking process.

(5) Cultivating independent thinking ability and innovation ability. Students' thinking ability is directly related to the effective use of information, affecting the viability of the information society. Open network environment allows students to more easily access information, if not independent thinking, it is easy to form blind obedience, and even lost. Therefore, we should pay attention to cultivating students the ability to think independently. Learning should also have modern consciousness and advanced consciousness, learning is an innovative activity, but also an invention, to advance with the times, with the help of modern information technology, the use of large network resources, learning across time and space.

\section{Carry Out Group Cooperation Learning Model}

Cooperation learning refers to students in order to complete the common task; there is a clear division of responsibilities of the mutual learning. Cooperation learning encourages students to work together for the collective and individual interests. The group usually consists of two or six students with different abilities. Under the premise of promoting the learning level of each person, improving the overall performance and achieve learning aims in the course of accomplishing common tasks.

Cooperation learning is a problem or task to present learning objectives, and to seek solutions to problems or tasks to carry out learning activities. Therefore, it is the key to the success of the cooperative learning teaching to design the cooperative task. Cooperation learning tasks require the following characteristics: First, operational, cooperative tasks require a lot of operational work, students in a limited time can not rely on personal power alone to complete, must rely on collective power; the second is the complexity of the ideal of cooperation The task should have some complexity. It does not require a high degree of difficulty, but should contain the cultivation of a variety of abilities; third, openness, through open discussion, help students to discover new problems and improve the difficulty of the problem, to provide students with The students can acquire the experience of scientific research, which is conducive to cultivating the spirit of cooperation and communication skills, and realizing the balanced realization of the cognitive, emotional and technical goals of inquiry learning. Teachers in the layout of cooperative tasks should be good at setting the problem situation. The role of cooperative contexts is to establish common values and understanding of differences. Through a meaningful situation presents cooperation tasks, in order to stimulate the interest of cooperation. Therefore, it is important to maintain coherence between the collaborative tasks and the content of the instruction. Only when the learning interest is stimulated, only has the intense cooperation motive.

Chinese reading teaching focuses on the subject of "teaching and learning". The thinking of teachers and students is rich in language communication. Individuality develops in cooperation and interaction, and improves the students' Chinese accomplishment comprehensively through cooperative reading. The implementation of cooperative learning in the Chinese reading teaching to provide students with more opportunities for students to become the master of learning, consciously feel the language, since the language learning, freedom to create language, the process of cooperation play autonomy, research and Creativity, to impart a simple knowledge of language and instrumental training, will be transferred to study, to enhance thinking and encourage innovation up. Cooperative learning has opened a new perspective for the reform of Chinese reading course. The use of cooperative learning in language reading teaching emphasizes the students' communicative competence and pragmatic competence, not only to understand and master the general language, but also to emphasize the common learning and co-creation of teachers and students, to enhance language expression in interactive dialogue and communication., Rich language content.

It is helpful for the teachers to improve the teaching by carrying out after-school follow-up investigation, collecting feedback information, reflecting the achievements and deficiencies, and carrying out comprehensive evaluation on the cooperative learning. Teachers collect information through class observation, assignment correction and conversation with students; reflect on the 
experience and shortcomings, for each group's performance to do specific guidance to promote each group to reflect on the formation of a virtuous circle of cooperative learning group.

\section{Implementation Strategies on Chinese Reading Teaching under the Network Environment}

In the theory of constructivist education, the process of knowledge formation is not a simple process of teachers 'transmission or award, but the process of students' active construction of new information according to their own knowledge. Network reading teaching model, students through the text of the query, reading and comparison, combined with the existing experience and gradually formed a distinctive personality of the concept of knowledge to complete the active construction. As an effective complement to the teaching of Chinese reading, network reading teaching will play a more important role in the implementation process to follow the following strategy:

(1) The reading process to take into account the students' reading personality. Reading is a personal behavior of students; teachers should not replace the reading practice of students, to cherish the unique feelings of students, experience and understanding. In the process of reading, students should have "their own views, judgments, experiences and questions," clear "reading is personalized behavior" of the scientific concept. "Reading individuality" refers to the individual psychological characteristics of the reading subject, and it is understood in the network reading. It mainly refers to the behavioral characteristics and emotional attitudes that students display when they read the article. Network reading to adapt to students lively, quick thinking and personalized development of the special needs for the autonomy of play open up a vast space. Therefore, students with different psychological characteristics of personality, rich in free online reading gradually formed a distinctive reading personality. A large number of diversified information easily leads to the formation of students' reading personality.

(2) Constructing inquiry Chinese reading teaching mode. In the teaching process, under the guidance of the teacher, the inquiry teaching mode is to study independently and explore the main knowledge points of the teaching content through the learning method characterized by "autonomy, inquiry and cooperation". So as to better meet the curriculum standards on the cognitive goals and emotional goals of a teaching model. The network becomes the necessary tool for students to analyze and solve problems. In the process of inquiry, the students' ability of summarizing and summarizing is improved, and the ability of research and exploration is also improved. Students in addition to independent thinking, but also need division of labor, joint research and cooperation and exchange, help to develop collaborative skills. There is no so-called "standard answer" in the teaching of inquiry-based reading, and all kinds of answers provided by the students provide a broad space for individual development and develop the students' innovative ability. Network environment for students to provide independent and independent learning space, students learn according to their own interests, and this learning extends to the classroom, to stimulate learning initiative.

(3) Establishing a new type of equal relationship between teachers and students. In the traditional teaching of reading, the teacher is in the absolute position of authority. Under the network environment, the relationship between teachers and students has been fundamentally changed. In the process of teaching, students and teachers face the text; the students no longer face the teacher's intention, but the information for the media and teachers to exchange information. Learning behavior directly to the teaching plan, students have greater autonomy. The relationship between teachers and students is based on the network, the relationship between teachers and students in a relatively equal position, reading teaching all the information is no longer a teacher's patent, between teachers and students of the traditional "grant relationship" has undergone a complete change. Teachers from the podium to go down to the teaching process as an ordinary member of the identity of the students involved in learning activities, and students to explore, exchange and dialogue.

(4) Strengthen the students' information literacy training. Information literacy includes information consciousness, information ability, information morality and lifelong learning ability and so on. Information awareness is the ability to understand, perceive and evaluate information, 
information sources, efficient access to information, processing of assessment information, and effective use of information, which are generated by people's theories, perspectives, things and phenomena. Information literacy, which refers to the moral norms that people should follow in information activities, including intellectual property rights, personal privacy, resisting bad information, etc.; lifelong learning ability, ability to acquire lifelong learning is the goal of information literacy education. Information literacy, as a kind of advanced cognitive skill, together with the ability of critical thinking and problem-solving, forms the basis of students' knowledge innovation and how to learn. When the network and language teaching integrated as a whole, the bridge between the two is to improve the information quality of students.

(5) Improving the evaluation mechanism of Chinese reading teaching under the network environment. Teaching evaluation is based on teaching objectives, the teaching process and the results of value judgments, and teaching decision-making services, teaching activities is the reality or potential value of the process of making judgments. Teaching evaluation generally includes teachers, students, teaching content, teaching methods, teaching environment and teaching management and other factors of the evaluation, but mainly for student learning and teaching evaluation of teachers. Traditional teaching evaluation is based on the teaching objectives, the use of examination or examination and other means to collect students in the process of teaching and self-learning changes in cognitive behavior, and then the student's cognitive ability and level of judgment. Network teaching needs open and multi-dimensional evaluation mode, mainly from the process and effect of two aspects. In the evaluation of the main, emphasis on student self-evaluation; in the evaluation function, pay attention to play the evaluation of the educational function; in the evaluation type, the emphasis on the implementation of formative evaluation in the evaluation method, the more use of relative evaluation method.

\section{References}

[1] J. Zhang, J. Zhang, Z. H. Shi, "Research on Chinese reading teaching based on Network Environment," Education Teaching Forum, vol. 7, no. 7, pp. 225-226, 2015.

[2] C. M. Zhou, "On the teaching of Chinese reading under the network environment," Software Guide, vol. 12, no. 11, pp. 197-199, 2013.

[3] X. R. Song, "A research of High school Chinese reading teaching mode building under the network environment," Master's degree of Zuzhou University, 2015.

[4] M. Xu, "Research on the teaching strategies of Chinese reading in primary school under the network environment," Asia-Pacific Education, vol. 3, no. 27, pp. 20-20, 2016.

[5] S. Y. Sun, "The research of Chinese reading teaching under the network environment," Master's degree of Tianjin Normal University, 2011.

[6] G. Q. Li, "The exploration of Chinese reading teaching mode under the network environment," China Education Info, vol. 18, no. 2, pp. 51-53, 2012.

[7] Q. Y. Gu, "On the superiority of Chinese reading teaching under the network environment," Yangtz Delta Magazine, vol. 4, no. 11, pp. 56-57, 2012. 